\title{
AODV, DSDV and OSLR Protocols Performance over MANET
}

\author{
Amit Garg, Ashish Kumar, Amit Chaturvedi
}

\begin{abstract}
As each mobile node of a MANET is treated as an autonomous peer, and the random mobility patterns of the mobile nodes need to be analyzed to obtain the performance of the continuously changing topology network. Many mobility models are designed and analyzed to the real-world scenarios with limited communication resources. MANETs belong to Wireless Networks where the nodes communicate with each other in a multi-hop fashion without any centralized control. Such network is infrastructure less, resource constrained, works in dynamic topology to provide communication. As routing performs a crucial role for obtaining the path from source to the destination, so mobility modeling and control makes the topology more challenging. Here, in this paper we have compared three routing protocols with $A O D V, D S D V$, and $O L S R$ for the ten samples by varying number of nodes and number of packets sent on the network and obtained the cases where these protocols perform best. OLSR performs well in the less crowd networks than the AODV and DSDV. AODV performs better than when the number of nodes is less than five in our sample.
\end{abstract}

Index Terms: MANET, AODV, DSD, OLSR, PDR, Protocol.

\section{INTRODUCTION}

As nodes in MANET have nature to move and due to this reason, topology of the network also changes regularly. Hence the Multi-hop route changes due to the changes in the underlying network topology. The routing protocols should have to deal with all these network topology changes. There are two main tasks for such routing protocols: (1) Keep the updated network topology status, and (2) Updating the routing table for the best possible route [1], [2] and [3]. For keeping the track of present network topology following are the important parameters like, the speed of mobility, number of nodes, area of network, mobility model etc. There are some restrictions of resources in the network, as the resource are limited in any network, these restrictions are also called network overheads. The performance of a network routing protocols depends on the following parameters like packet end-to-end delay, PDR ratio, and routing overhead. The mobility of the node is the important factor because it affects the network topology, route mapping and other overheads of the network [4] and [5].

QoS routing is a routing process that guarantees to support to a set of QoS parameters during establishing a route. To achieve QoS every mobile node must implement traffic conditions, buffer management, and queue scheduling schemes [6] and [7]. There are two known approaches that

Revised Manuscript Received on 20 September, 2019.

Amit Garg, IFTM University, Moradabad, UP, India

Ashish Kumar, I.T.S Engineering College, Greater Noida, UP, India

Amit Chaturvedi, Govt. Engineering College Ajmer Rajasthan, India utilize routing protocols in order to provide QoS in MANETs. The first one tries to embed end-to-end minimum QoS guarantees (delay, bandwidth) in the computation of the routing algorithm. The routing protocol will request for a connection with a minimum required bandwidth and find the optimum route that can best satisfy that requirement. Core-Extraction Distributed Ad-Hoc Routing (CEDAR) is an example of use of this approach. The second approach is an extension to AODV that takes routing into account to satisfy QoS requirements [8].

\section{ROUTING PROTOCOLS IN AD-HOC NETWORKS}

Mobile Ad-Hoc networks are self-organizing and self-configuring multi-hop wireless networks, where the structure of the network or the topology changes dynamically. All the nodes are mobile and share the random access wireless channel. One of the node may reacts like a router and there is no infrastructure support. So, routing procedures are required and routes or paths are obtained before transferring data from source to destination.

The ad-hoc routing protocols must have properties like they should support distributed operation, routes supplied should be loop free, protocol should react only when needed and should not periodically broadcast control information, unidirectional link support, security, power conservation, multiple routes, quality of service support.

Because the topology of the network changes dynamically due to nodes mobility, thus the routes or paths are also changes from source to destination. There are some problems or overheads in routing with MANET like asymmetric links, routing overhead, interference, and dynamic topology [10] and [11].

Proactive protocols attempt to maintain consistent, up-to-date routing information from each node to every other node in the network. There is constant propagation of routing information periodically even when topology change does not occur. Substantial traffic and power consumption incurs with proactive protocols, which is generally limited in nodes of MANET. In case of proactive protocols, a route is always available to every other node in ad-hoc network and the first packet latency is less when compared with on-demand protocols [12]

In case of Reactive protocols, a route is built only when required. Periodic updates are not done in reactive protocols and control information is not propagated unless there is a change in the topology [13]. Considerably traffic and power consumption does not sustain

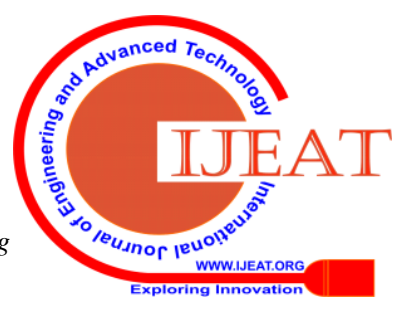


compared to Proactive routing protocols [14]. If compare it with the proactive routing protocols, the first packet latency is more, because in reactive protocols the new route is obtained when needed to send packets and no predefined routes, as the nodes are mobile.

\section{CONCLUSION}

From the results, OLSR outperforms when number of packets was 50, when number of packets increased from 100 and 500, OLSR and DSDV outperforms than AODV. If we compare between OLSR and DSDV, PDR ratio degrades in case DSDV when number of nodes increased by 20 , even though it is much better than the AODV in these cases also. When the number of nodes is very less i.e. less than 5, AODV outperforms DSDV.

So, it is concluded that OLSR outperforms than AODV and DSDV when the number of nodes are more than 20 and AODV performs better only in those cases when number of nodes was less than 5 . Hence, according to the simulation results OLSR outperforms AODV and DSDV.

\section{ACKNOWLEDGMENT}

The authors are thankful for all the experts who contribute to prepare this research paper directly or indirectly.

\section{REFERENCES}

1. Ayaz Ahmad, Mahfuzul Huda, Mohd Atif Kaleem, Rajendra Kr Maurya, "Mobile Ad-Hoc Networks: AODV Routing Protocol Perspective", International Journal of Advanced Research in Computer and Communication Engineering (IJARCCE) Vol. 4, No. 12, (2015).

2. Gulfishan Firdose Ahmeda, Raju Barskarb, Nepal Barskarc, "Improved DSDV Routing Protocol for Wireless Ad Hoc Networks", International Conference on Communication Computing \& Security (ICCCS-2012), Vol. 6, pp. 822-831, (2012).

3. Lakrami F., Elkamoun N., El Kamili M., "A Survey on QoS for OLSR Routing Protocol in MANETS, International Symposium on Advances in Ubiquitous Networking", Lecture Notes in Electrical Engineering, Vol. 366, pp. 287-300, (2016).

4. B. Divecha, A.Abraham, C.Grosam and S.Sanyal, "Impact of Node Mobility on Manet Routing Protocols Models", Journal of Digital Information Management, Vol. 5, pp. 19-26, (2007).

5. A. Garg, A. Kumar, A. Chaturvedi, "A Study on Quality of Service Requirements in MANET Especially Focusing Efficient Routing Procedures", International Journal of Computer Trends and Technology (IJCTT), Vol. 51, No. 1, pp. 27-29, (2017).

6. D. S. Devi and Dr. G. Padmavathi, "Impact of Mobility for QoS Based Secure MANET", International Journal on Applications of Graph Theory in Wireless Ad hoc Networks and Sensor Networks, Vol.2, No.3, pp. 46-57, (2010).

7. I. Vijaya, Amiya Kumar Rath, Bhagabat Puthal, Debahuti Mishra and S. Satapathy, "Performance Analysis of QoS Parameters of MANET on Mobility and Energy based Model with Different MANET Routing Protocols", Indian Journal of Science and Technology, Vol. 9, No. 37, (2016).

8. P. Sinha, R. Sivakumar and V. Bharghavan, "CEDAR: a core-extraction distributed ad hoc routing algorithm", INFOCOM '99. Eighteenth Annual Joint Conference of the IEEE Computer and Communications Societies. Proceedings. IEEE, New York, pp. 202-209, (1999).

9. Said El Kafhali, Abdelkrim Haqiq, "Effect of Mobility and Traffic Models on the Energy Consumption in MANET Routing Protocols", International Journal of Soft Computing and Engineering (IJSCE), Vol. 3, No. 1, (2013).

10. Mohamed Amnai, Youssef Fakhri, Jaafar Abouchabaka, "Impact of Mobility on Delay-Throughput Performance in Multi-Service Mobile Ad-Hoc Networks", Int'l J. of Communications Network and System Sciences, Vol. 4, pp. 395-402, (2011).

11. S.R. Biradar, S.K. Sarkar, Rajanna KM, Puttamadappu C., "Analysis QoS Parameters for MANETs Routing Protocols", International Journal on Computer Science and Engineering, Vol. 02, No. 03, pp. 593-599, (2010)
12. Fahim Maan, N. Mazhar, "MANET Routing Protocols vs Mobility Models: A Performance Evaluation”, ICUFN, pp. 179-184, (2011).

13. Hannan Xiao, W. K. G. Seah, A. Lo and K. C. Chua, "A flexible quality of service model for mobile ad-hoc networks", VTC2000-Spring. 2000 IEEE 51st Vehicular Technology Conference Proceedings (Cat. No.00CH37026), Tokyo, vol.1, pp. 445-449, (2000).

14. D. N. Patel, S. B. Patel, H. R. Kothadiya, P. D. Jethwa and R. H. Jhaveri, "A survey of reactive routing protocols in MANET", International Conference on Information Communication and Embedded Systems (ICICES2014), Chennai, pp. 1-6, (2014). 